will become their slaves in the next world; and Sir Hugh Low states that among the Kayans, before a person can be buried, a head must be obtained. Several travellers are of opinion that the passion for head-hunting, which now characterises these people, was not formerly so deeply rooted in their characters as it is at present, although to a limited extent it is probably an ancient custom. The second reason is a fairly satisfactory explanation of the origin of the custom, and the first for its extension, as the fact of a young man being sufficiently brave and energetic to go head-hunting would promise well for his ability to keep a wife.

The religious observances of the Land Dyaks consist of setting aside of a portion of fowl and pig-meat for the deity; the propitiation by small offerings of rice, \&c., of Antus, or spirits (of these there are two kinds, demons and ghosts of.departed men); the pamati, or taboo; obedience to the medicine women, and belief in their pretensions ; dancing; the use of omens from the notes of various birds.

On reading this book, one is constantly reminded how much more information must be collected before a complete record of the people can be gained; as Mr. Lang a student at home finds in endeavouring to interpret the significance of a native pattern, we have only to look at the design to the left in the illustration on p. 38 of $\mathrm{Mr}$. Ling Roth's book, which, without a clue, could never have been imagined to indicate a cloudy sunset.

Sufficient has been said to show that this book is a valuable storehouse of information, and it also reflects great credit on the publishers for the artistic manner in which it has been produced. An idea of the character of the illustrations may be gained from the three which accompany this notice.

ALFRED C. HADDON.

\section{THE ALLOYS OF COPPER AND ZINC.}

$\mathrm{N}$ account of their great industrial importance, the alloys of copper and zinc have at various times been studied by many observers. Mallet, Matthiessen, Riche, Thurston, and a host of others have made contributions of varying importance to the literature of the subject; but so difficult is it to eliminate the accidental differences in the physical conditions that Prof. Thurston announced, as late as the year 1893, that the curves representing the variations in the properties of brasses
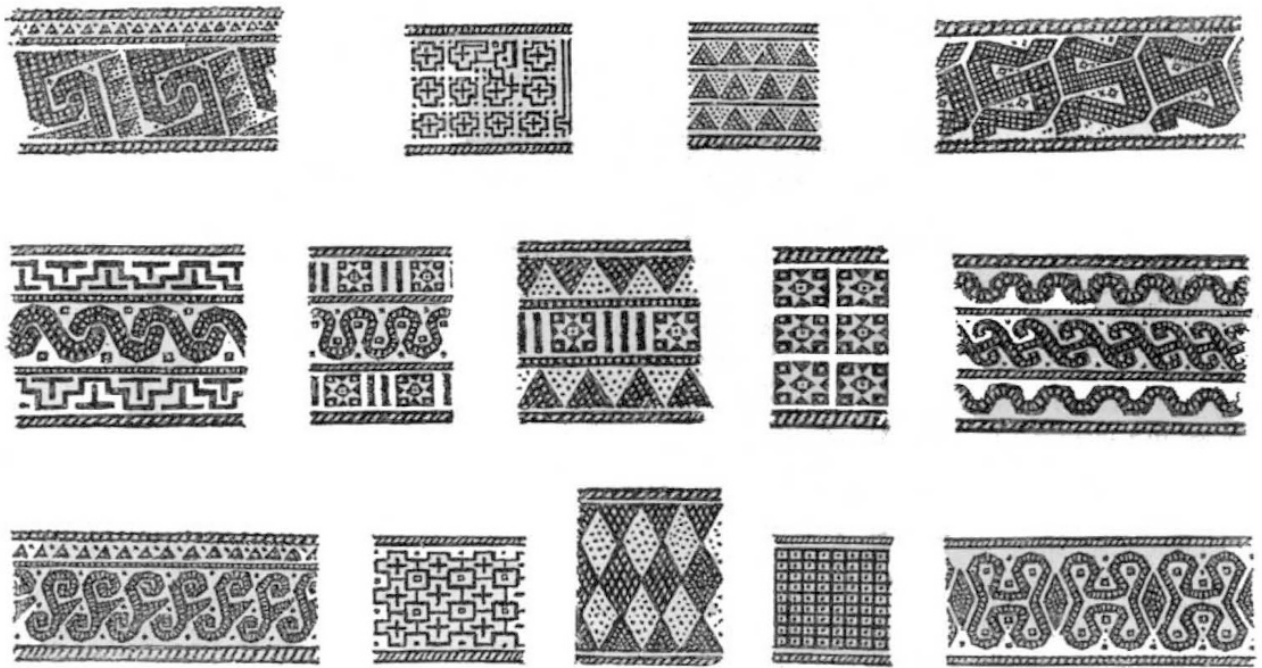

FIG. 3.-Patterns on Kanowit Bas'sets in the Brooke-Low Collection.

points out in his preface, "the writers quoted by $\mathrm{Mr}$. Ling Roth were not, or not usually, anthropologists who knew what to look for"; on the other hand, as Mr. Lang says, "inquirers who know what to look for, are only too likely to find it, whether it is there or not. This is the dilemma of anthropological evidence." It is to be hoped that the publication of this work will result in renewed and definitely directed observations on the spot.

One important line of inquiry, the significance of the decorative art, is totally unrepresented in the materials at Mr. Ling Roth's disposal. That this is a promising field for research is evidenced by a recent paper by Dr. W. Hein, "Zur Entwicklungsgeschichte des Ornaments béi den Dajaks" (Ann. k. k. Naturhist. Hofmuseums, Wien, Band $x$. Heft 2). This study deals only with anthropomorphic designs, but it is probable that the motives are much more varied. The characteristic and very effective designs on Bornean shields are also mostly derived from the human form.

To those who are conversant with the evolution of savage decorative art, it is evident that such patterns as those on Kanowit baskets have a significance which is at present unsuspected. As an example of the difficulty were so irregular that the effects of composition only (irrespective of other conditions) must remain unknown until further researches should be made. To the task thus indicated M. G. Charpy has addressed himself, and has succeeded in notably advancing the knowledge on the subject. ${ }^{1}$ He did not confine himself to the mechanical properties, but has also made a careful investigation of the micrographic properties of a number of alloys, a branch of the subject which had already been attacked by Guillemin and by Behrens in I 894 .

Among the results of the mechanical tests, none are more interesting than the determination of the effects of variation of the temperature used in annealing pieces of brass which had previously been hardened by repeated rolling. M. Charpy finds that, if the maximum temperature of annealing is maintained for some time, the mechanical and micrographical properties of test pieces of similar composition depend only on that temperature. The tensile strength of metallic copper, in kilogrammes per square millimetre, when annealed at different temperatures, is shown in Fig $I$, the shape of the curve

1 "Recherches sur les Alliages de Cuivre et de Zinc," by M. (i. Charpy (bull. de Soc. d'Encouragement, 5th series; vol. i. p. I8o, February 1806).

NO. I 4 I 5 , VOL. 55] 
A B C D being similar in the case of all the brasses. It may be seen that reheating has no effect on the tensile strength of copper unless the temperature exceeds $280^{\circ}$, when there is a progressive lowering of the tensile strength until the temperature reaches $420^{\circ}$. Above that point a further increase of temperature has no effect on the metal, the annealing being complete. Finally, when the temperature is so high that the copper is "burnt," the tensile strength again falls off rapidly.

It is remarkable, however, that the more thoroughly the test piece is hardened, and consequently the higher its initial tensile strength, the lower is the temperature (in the above instance, $280^{\circ}$ ) at which the annealing effect becomes sensible. M. Charpy suggests, therefore, that in pure, completely hardened copper or brass, any increase in temperature, above that at which the hardening was effected, would cause a reduction in the tensile strength, and that the broken curve C B A would then be a straight line, $\mathrm{C}$ B E. It would thus be predicted, as may be seen by a glance at the diagram, that the tensile strength of completely hardened pure copper would be about 52 kilogrammes per square millimetre, and, as a matter of fact, $A$. Le Chatelier raised the tensile strength

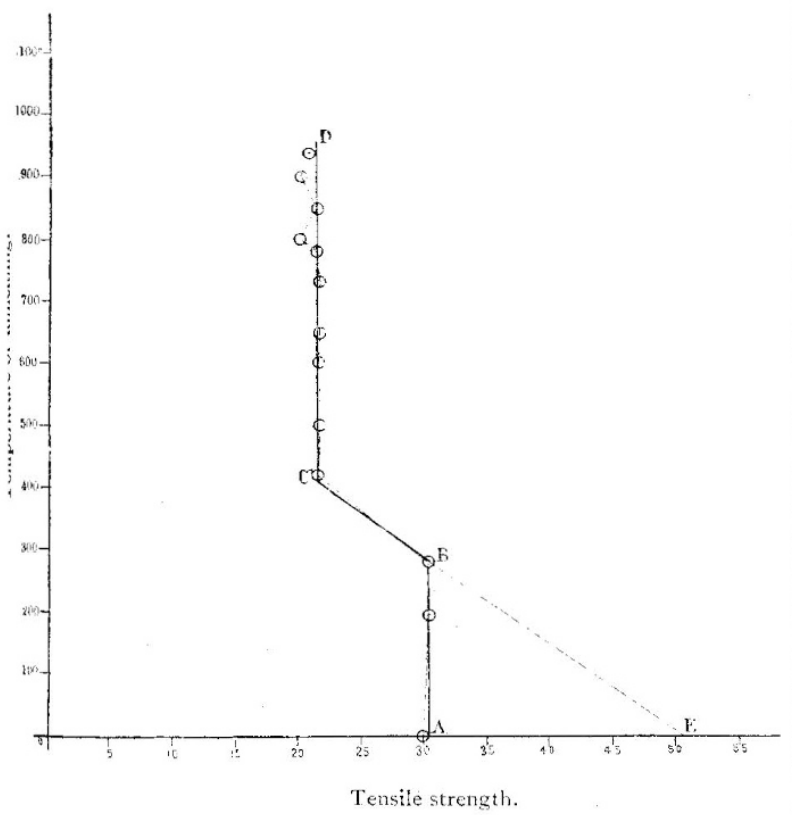

Fici. r.-Variations in the tensile strength of metallic copper.

of copper to jI kilogrammes by successive wire-drawings. In spite of this close agreement, the inference must be accepted with some caution, for apparently there were no experiments made on copper annealed at temperatures between $280^{\circ}$ and $420^{\circ}$. Nevertheless the approximate correctness of the general direction of the line $\mathrm{BC}$ is attested by a number of results obtained on the analogous parts of the curves obtained by studying the brasses, whence, for example, it may be deduced that the maximum tensile strength of the alloy containing $30^{\circ} 2$ per cent. of zinc should be about 70 kilogrammes per square millimetre, or 44 tons per square inch.

In tests made on completely annealed bars, in which M. Charpy believes that all accidental differences in the physical conditions are eliminated, he finds that the tensile strength increases with the percentage of zinc, passes through a maximum when the alloy contains about 45 per cent. of zinc, and then decreases rapidly. The elongation increases similarly with the percentage of zinc, but passes through a maximum when the alloy contains 30 per cent. of zinc, and then decreases rapidly. It follows that there is no advantage in using for industrial purposes alloys containing less than 30 per cent. of zinc, as they are more costly, and possess both less resistance and less malleability than those richer in zinc. On the other hand, if there is more than 43 per cent. of zinc present, the alloys are brittle, and should not be employed, so that only those with from 30 to 43 per cent. of zinc can be recommended for use.

In the micrographical researches, in which enlargements of 30 diameters with obliquely falling light were studied.

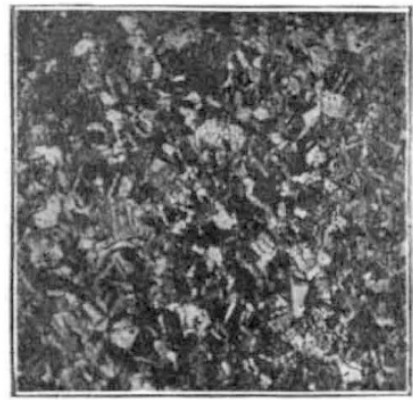

FIG. 2.-Alloy containing copper 80 per cent., zinc 20 per cent., annealeu at $700^{\circ}$.

appearances were noted by $\mathrm{M}$. Charpy corresponding to many of the results of the mechanical tests. Thus, for example, on hardening alloys containing from o to 35 per cent. of zinc by passing them through the rolls, the crystals are gradually deformed and disappear, a homogeneous granulated surface being obtained. When the hardened alloys are annealed, the crystals are reformed, their size depending on the maximum temperature attained, and not on the length of time during which they were subjected to it. No striking change is produced by reheating to temperatures below that at which

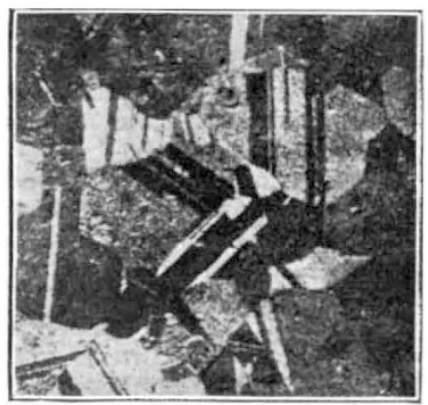

Fig. 3.- The same annealed at $900^{\circ}$, showng increase in the sime of the crystals.

complete annealing is effected, but above that temperature the alloys become completely crystalline, showing no amorphous magma, and the crystals grow larger and larger as the temperature is raised and the tensile strength falls off. Thus Fig. 2 shows an alloy containing 20 per cent. of zinc which has been hardened and annealed at $700^{\circ}$, and Fig. 3 shows the same alloy annealed at $900^{\circ}$. The crystals are octahedra with numerous macles, and are obviously larger in the latter case than in Fig. 2.

When the reheating is carried to a very high tem.

NO. I 4 I 5 , rOL. 55$]$ 
perature, near the melting point of the alloy, so that it is "burnt," a number of blowholes, looking like bubbles of gas, make their appearance (see Fig. 4, which represents commercial brass, containing 30 per cent. of zinc, after it has been annealed at $820^{\circ}$ ). As the temperature rises, these blowholes increase in number, and at the same time fissures develop round the crystals and eventually form a complete network. It appears that an alloy, not easily fusible, forms round the crystals, and, becoming liquefied, rounds off and corrodes them, thus giving the appearance of fissures. These effects are more readily produced if traces of lead and tin are present, as is usually the case in commercial brass, and the network round the crystals doubtless contains these metals. Under these circumstances the test pieces are of little tensile strength, and are not malleable.

M. Charpy prepares the alloys for examination with the microscope by etching the polished surface by electrolytic attack $\mathrm{He}$ points out that the fracture is useless as a guide to the mechanical properties of any metal or alloy. It has usually been supposed, owing to the appearance of the fracture, that a highly crystalline metal is necessarily fragile; but this is far from being the case. Brass may be mainly composed of crystals as much as one millimetre in diameter without any interstitial matter, and yet may have an elongation of 60

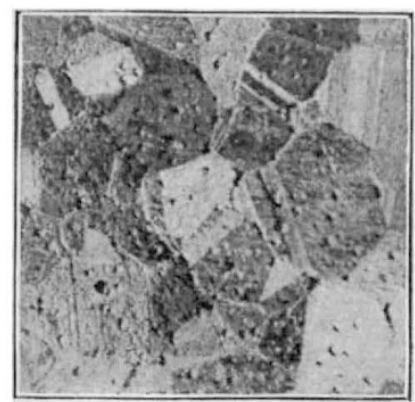

FIci 4.-Commercial brass, containing traces of lead and tin, "burnt" by being annealed at $820^{\circ}$.

per cent. The only deduction that can be drawn from the appearance of the fracture is that if the crystalline structure is revealed in this way, the metal is brittle and of little tensile strength.

The microscopic structure revealed by etching polished surfaces enables the alloys of copper and zinc to be divided into three classes - those containing less than 35 per cent. of zinc, those containing from 35 to 45 per cent. of zinc, and those containing more than 45 per cent. of zinc. It enables the observer to determine whether the metal has been cast, and, according to the size of the grain, whether the casting has been made at a high or a low temperature, and what is the nature of the mould. It shows the effects of hardening, of annealing at various temperatures, and, lastly, shows whether or not the metal has been burnt.

M. Charpy infers, from the identical appearance of the alloys containing less than 35 per cent. of zinc, that these all consist of isomorphous mixtures of copper with the compound $\mathrm{Cu}_{2} \mathrm{Zn}$, which contains about 66 per cent. of copper. He also confirms the existence of the compound $\mathrm{CuZn} \mathrm{n}_{2}$ containing $67^{\circ} 2$ per cent. of zinc, which forms a perfectly homogeneous alloy under all conditions, and finds that if more zinc than this is present, it remains in the free state soluble in potash. On the other hand, M. Charpy expresses no opinion as to the form in which the metals are present in the alloys containing more than 34 and less than 67 per cent. of zinc.

T. K. ROSE.

\section{DR. BENJAMIN APTFORP GOULD.}

$A$ NOTHER busy life, devoted to the advancement of A astronomy, is ended by the death of Dr. B. A. Gould. Practically, half a century has passed since his name came prominently before the public, in connection with the establishment of an astronomical journal in America, and throughout this period he has maintained a foremost place in the ranks of American astronomers by the unwearying energy he has exhibited, and the mass of work he has accomplished. For many years he was attached to the United States Coast Survey, where, under Superintendents Bache and Peirce, he did good service in the determination of longitudes at stations along the Atlantic seaboard, from New Orleans to the extreme north-eastern boundary of the United States. In those early days the employment of the method of telegraphic signals had not long been in use in America, and was scarcely known in Europe, and its subsequent development for longitude investigations owes much to the energy that Dr. Gould brought to bear upon problems of this character. When the Atlantic cable was successfully laid, he perceived the advantages it offered to connect the American with the European longitudes, and thus to practically reduce the two independent series of determinations into one complete system.

It was while engaged on the staff of the Coast Survey, and anxious in every way to promote its interests, that he became unfortunately embroiled with the Trustees of the Dudley Observatory. It is not necessary to make any further allusion to this unhappy affair, beyond expressing our belief that Dr. Gould was a much-injured and muchpersecuted man. Conducting, as he was at the time, an American journal of high repute, and fully employed on the affairs of the Coast Survey, he probably was illadvised to attempt to direct the Dudley Observatory, by giving to the institution the leisure that his other occupations permitted. But if he erred in judgment he suffered severely. That there is abundant evidence to show ; but that his reputation rose above the attacks of his persecutors, is a matter for congratulation. The Dudley fiasco came about in 1859, and in the next year Abraham Lincoln was elected to the Presidency, the war of Secession was imminent, and with the troubles that supervened, the Astronomical Journal was suspended. Not that Dr. Gould's industry was less. A glance at the Royal Society's catalogue of papers shows a long list attached to his name, and some of them, such as the reduction of D'Agelet's observation, involved considerable labour. It is possible here, however, only to refer to his best-known work, the successful establishment of an observatory at Cordova, and the great amount of work therein accomplished. The observatory itself is the outcome of a private expedition that Dr. Gould planned to the Argentine Republic, in order to extend to the southern hemisphere the system of zone observations that Bessel and Argelander had applied to the north. This private expedition was welcomed and adopted by the Argentine nation, and led to the foundation of that national observatory under whose auspices those valuable and extensive catalogues have been published, and whose preparation kept Dr. Gould at Cordova some fourteen years. While waiting for the full instrumental equipment of the observatory, Dr. Gould and his assistants occupied themselves with the preparation of charts of the southern hemisphere, giving the position of those stars that could be seen with the naked eye, and assigning to them magnitudes, which practically extended Argelander's scale to the whole hearens. For this work he was awarded the Gold Medal of the Royal Astronomical Society; he had been elected a foreign associate in 1855 .

Dr. Gould on leaving South America returned to Boston. Here, in 1886 , after an interruption of twenty-

NO. 14 I5, VOL. 55] 